Сравнительный анализ стратегий управления брендом

\begin{tabular}{llll}
\hline \hline Юлия О. Лящук, & 1 & ularzn @ mail.ru & (D) 0000-0002-3612-1707 \\
Ольга В. Платонова 2 & platva-82@mail.ru & (1) 0000-0002-3259-1031 \\
\hline
\end{tabular}

1 Московский университет имени С.Ю. Витте (филиал в г. Рязань), Первомайский проспект, 62, г. Рязань, Россия

2 Академия права и управления Федеральной службы исполнения наказания, ул. Сенная, д.1, г. Рязань, Россия

Аннотация. В статье представлены результаты анализа трёх основных стратегий, входящих в систему управления брендом. Управление брендом предполагает разработку долгосрочного плана, который детально описывает формирование стратегических образов и имиджа бренда, предполагаемую динамику его развития бренда, и реакцию на изменения внешней среды, рынка и потребительских представлений. Стратегии управления используются для достижения ключевых целей развития бренда. В первую очередь, брендовая продукция должна быть уникальной и выгодно отличаться от продукции конкурентов, что на сегодняшний день в условиях глобализации довольно сложно. Стратегическое управление брендом позволяет решить эту задачу, проанализировав ситуацию на рынке и применив необычные методы привлечения внимания потребителей. Для того, чтобы увеличить значимость продукции необходимо выстроить эмоциональную и доверительную связь с контактной аудиторией. Тонко выстроенная эмоциональная связь позволяет обрести клиента, которому не только подходит продукт, но и который порекомендует его своему ближнему окружению. Когда брендинг создает эмоциональную связь с клиентами, это позволяет увеличить долю рынка, получить большую отдачу в денежном эквиваленте и развивать бренд. В условиях жёсткой конкуренции на современных рынках занять прибыльную нишу новым брендам очень тяжело. Но стоит помнить, что раскрученные бренды приобрели популярность благодаря определенным стратегиям, которые будут весьма эффективны и сегодня. Управление брендом включает в себя три, взаимосвязанных в единый комплекс, стратегии: стратегию продвижения бренда, рекламную стратегию бренда и стратегию позиционирования бренда. Многие предприятия и организации, признавая ценность и позитивное влияние сильного бренда на уровень продаж, прописывают стратегию построения и будущего развития бренда довольно расплывчато. Стоит помнить, что стратегическое управление брендом необходимо не только тогда, когда создается новый бренд, но и в тех случаях, когда нужно реанимировать или обновить уже существующую торговую марку.

Ключевые слова: стратегия продвижения, бренд, реклама, стратегия, позиционирование бренда

\title{
Comparative analysis of brand management strategies
}

\begin{tabular}{llll}
\hline \hline Yuliya O. Lyashchuk & 1 & ularzn@ mail.ru & (D) 0000-0002-3612-1707 \\
Olga V. Platonova & 2 & platva-82@mail.ru & (D) 0000-0002-3259-1031 \\
\hline
\end{tabular}

1 Moscow University named after S.Y. Witte (Ryazan branch)

2 Academy of Law and Management of the Federal Service for the Execution of Punishment

Abstract. The article presents the results of the analysis of three main strategies included in the brand management system. Brand management involves the development of a long-term plan that describes in detail the formation of strategic images and brand image, the expected dynamics of its brand development, and the response to changes in the external environment, market and consumer perceptions. Management strategies are used to achieve key brand development goals. First of all, branded products must be unique and differ favorably from competitors' products, which today is quite difficult in the context of globalization. Strategic brand management allows you to solve this problem by analyzing the market situation and using unusual methods to attract the attention of consumers. In order to increase the value of the product, it is necessary to build an emotional and trusting connection with the contact audience. A finely built emotional connection allows you to find a client who is not only suitable for the product, but also who will recommend it to his closest environment. When branding creates an emotional connection with customers, it allows you to increase market share, get more value for money, and grow your brand. In the face of tough competition in today's markets, it is very difficult for new brands to occupy a profitable niche. But it is worth remembering that the promoted brands gained popularity thanks to certain strategies that will be very effective today. Brand management includes three, interconnected in a single complex, strategies: brand promotion strategy, brand advertising strategy and brand positioning strategy. Many businesses and organizations, while recognizing the value and positive impact of a strong brand on sales, are rather vague about their brand strategy and future development. It is worth remembering that strategic brand management is necessary not only when a new brand is being created, but also in those cases when it is necessary to revive or renew an existing trademark.

Keywords: promotion strategy, brand, advertising, strategy, brand positioning

\section{Введение}

Стратегическое управление брендом позволяет решить задачу по формированию имиджа уникальности продукции. Для повышения значимости продукции в глазах потребителей с аудиторией необходимо выстроить эмоциональную и доверительную связь.

\section{Для цитирования}

Лящук Ю.О., Платонова О.В.Сравнительный анализ стратегий управления брендом //Вестник ВГУИТ. 2021. Т. 83. № 1. С. $343-352$ doi:10.20914/2310-1202-2021-1-343-352
Тонко выстроенная эмоциональная связь позволяет обрести постоянных клиентов, которые будут в восторге от продукта и порекомендует его своему ближнему окружению. Когда брендинг создает эмоциональную связь с клиентами, это позволяет увеличить долю рынка, получить большую отдачу в денежном эквиваленте и развивать бренд [3].

$$
\text { For citation }
$$

Lyashchuk Yu.O., Platonova O.V. Comparative analysis of brand management strategies. Vestnik VGUIT [Proceedings of VSUET]. 2021. vol. 83. no. 1. pp. 343-352. (in Russian). doi:10.20914/2310-12022021-1-343-352

This is an open access article distributed under the terms of the Creative Commons Attribution 4.0 International License 
Важно помнить, что, создавая бренд, необходимо учесть не только физические свойства товара, но и чувства, вызываемые у потребителей. Производится концентрация не только на сознании, но и на эмоциях и подсознании. Эмоциональные воздействия являются крайне эффективными, а управление эмоциями позволяет влиять на волевую сферу потребителей через эмоциональные состояния [4].

Стратегии управления используются именно для достижения этих ключевых целей развития бренда. В условиях жёсткой конкуренции на современных рынках занять прибыльную нишу новым брендам очень тяжело.

Известные бренды приобрели популярность благодаря определенным стратегиям, которые будут весьма эффективны и сегодня.

Стратегическое управление брендом необходимо не только тогда, когда создается новый бренд, но и в тех случаях, когда нужно реанимировать или обновить уже существующую торговую марку.

Система управления брендом включает в себя три, взаимосвязанных в единый комплекс, стратегии:

- стратегию позиционирования бренда;

- стратегию продвижения бренда;

- рекламную стратегию бренда.

Каждая из этих стратегий имеет свои особенности и разновидности воплощения.

\section{Объекты и методы}

Объектом исследования являлись три основных стратегии управления брендом: стратегия позиционирования бренда, стратегия продвижения бренда и рекламная стратегия бренда.

Предметом исследования являлись особенности применения стратегий каждого вида и результативность их воздействия на контактную аудиторию.

Исследования были проведены стандартными методами статистического и сравнительного анализа на основе данных маркетинговых исследований, проведённых международным рейтинговым агентством «Fitch Ratings Inc.», исследовательской компанией «FDF Group» (рейтинги брендов) и маркетинговыми агентствами «MegaResearch» (Москва) и «Infowave» (СанктПерербург).

\section{Обсуждение}

Рассмотрим особенности каждой из стратегий в комплексе управления брендом.

Наиболее важное место среди них занимает стратегия позиционирования бренда.
Существует несколько концепций позиционирования бренда, которые впервые описал маркетолог, основатель и президент консалтинговой фирмы «Trout\&Patners» Джек Траут, который так же является одним из авторов маркетинговых исследований «позиционирования» и маркетинговой войны. Его статья была опубликована в журнале «Industrial Marketing» в 1971 году. Это он придумал основополагающие концепции позиционирование и дифференцирование [1].

В современном мире данная разработка позиционирования одна из первых и самых важных работ в процессе создания бренда. Без таких разработок нелегко соорудить результативную и продолжительную маркетинговую стратегию.

Позиционирование - это деятельность, сосредоточенная на поиске конкретной рыночной позиции, способной выгодно отличить товар, компанию или услугу от конкурентов, занятии и поддержании этой позиции, формировании в сознании потребителя соответствующего образа товара, компании или услуги. Благополучное позиционирование дает возможность не только занять свое место на рынке, но и обеспечить дополнительным конкурентным преимуществом [2].

То есть позиционирование бренда - это работа, направленная на создание такого образа этого бренда, который поможет потребителю выделить его среди конкурентов и отдать ему предпочтение при покупке.

Позиционирование товара или услуги для потребителя - это способ идентификации того или иного товара или услуги, основанный на важнейших для потребителя характеристиках [5].

Чаще всего работа по организации и обеспечению позиционирования происходит следующим образом:

1 этап - сегментация рынка. Выбрать сегмент рынка, на котором будет представлен товар или услуга;

2 этап - изучить потребности потребителей на данном сегменте рынка, изучить предложения в нем, продумать свои преимущества для последующего построения позиционирования;

3 этап - разработать позиционирование на основе полученных конкурентных преимуществ;

4 этап - подкрепление позиционирования в рекламе, форме и упаковке товара и т. д.

Существует 4 базовых разновидности стратегии позиционирования [1]:

1 - оборонительная (только маркетинговый лидер может позволить себе оборону);

2 - наступательная (только маркетинговый лидер может позволить себе наступление);

3 - фланговая (осуществляется в отношение рынков, на которых никто ничего не делает);

4 - партизанская (для небольших «игроков», которые могут найти свою нишу и зацепиться на ней). 
В каждой стратегии существуют определенные принципы.

К принципам оборонительной стратегии можно отнести:

1. Оборонительная стратегия - это игра только для маркетингового лидера. Несмотря на то, что это кажется очевидным, все не так легко. На самом деле не сама компания создает себя как лидера, а потребитель делает из обычного продукта бренд.

2. Лучшая стратегия обороны - это готовность атаковать самого себя. Другими словами, лидер должен иметь возможность производить товар или услугу, которая превосходит их же предыдущий товар.

3. Сильные шаги конкурентов всегда нужно блокировать. В случае если компаниялидер упустила шанс атаковать себя, она может быстро скооперироваться и повторить шаги конкурентов, чтобы они не смогли закрепить свое положение.

Важно помнить, что «война» происходит в умах потребителей и новой атакующей компании требуется некоторое количество времени, чтобы получить положительное впечатление, в этот момент лидеру предоставляется достаточное количество времени для прикрытия своих сторон [6].

Принципы наступательной стратегии:

1. Как правило, реализует стратегию наступления чаще всего лидер.

2. Необходимо найти ваше слабое место и направить свои сильные стороны на его преобразование, пытаться целенаправленно осуществить наступательную кампанию в борьбе с лидером.

3. Принципы фланговой стратегии:

1. Чаще всего, эта стратегия применима в сторону рынков, где еще никто не занял необходимое место.

2. Необходим элемент неожиданности, в борьбе с конкурентами для того, чтобы они не могли скопировать ваш шаг достаточно быстро.

Принципы партизанской стратегии:

1. Небольшой компании проще всего найти маленький сегмент на рынке, который она будет в силах защитить.

2. Необходимо правильно рассчитать свои силы, которые будут положены на защиту сегмента, нельзя себя переоценивать.

3. В случае, когда на занятый сегмент приходит более сильная компания, необходимо иметь гибкость и быть готовым либо найти выход из ситуации, либо уходить с рынка.

В условиях жёсткой конкуренции на современных рынках занять прибыльную нишу новым брендам очень тяжело. Но стоит помнить, что раскрученные бренды приобрели популярность благодаря определенным стратегиям продвижения, которые будут весьма эффективны и сегодня.
Выделяют следующие аспекты формирования успешного бренда в рамках стратегии продвижения:

- создание комплекта осведомлённости;

- создание ощущения качественности;

- создание лояльности к бренду;

- создание позитивных ассоциаций с брендом;

- забота о клиентах (играет крайне важную роль в продвижении брендовых автомобилей, косметики и бытовой техники).

В настоящее время выделяют 5 наиболее действенных форматов стратегии продвижения бренда:

1 - стратегия мифопроектирования;

2 - стратегия эпатажа;

3 - стратегия «звёздного стиля»;

4 - спонсорская стратегия;

5 - трендовая стратегия.

Рассмотрим более подробно формирование стратегии продвижения бренда на примере брендов одежды.

Когда люди покупают брендовые элементы одежды, их волнует только сам факт обладания брендовой вещью. Поскольку, таким образом они повышают собственный статус среди своего социального слоя. Именно за счёт этого и существуют дорогие бренды одежды.

В своей книге «Построение бренда в сфере моды [1]: от Armani до Zara» Марк Тангейт показывает нам на примере большого количества брендов одежды, какой путь они прошли и как они его проходили. При этом у каждого бренда были свои особенности продвижения и существенные различия на пути их становления по сравнению с остальными. Из чего следует вывод, что нет какой-то одной единственной формулы, которая сама, автоматически создаст престижный бренд.

Существует множество вариантов, и надо суметь правильно соединить их воедино для реализации идеи.

1. «Chanel». Создавая свой бренд, Шанель взяла за основу инструментарий мифопроектирования, который продолжает использоваться компанией до сих пор. Каждую выпускаемую продукцию бренд связывает с личностью самой Коко, ставшей иконой стиля «Chanel».

Самыми яркими составляющими бренда «Chanel» являются (рисунок 1):

- приталенный жакет;

- маленькое чёрное платье;

- сумка на цепочке;

- крупная бижутерия (броши-камелии и искусственный жемчуг);

- духи «Chanel № 5» и «Сосо» ставшие парфюмерным бестселлером. 

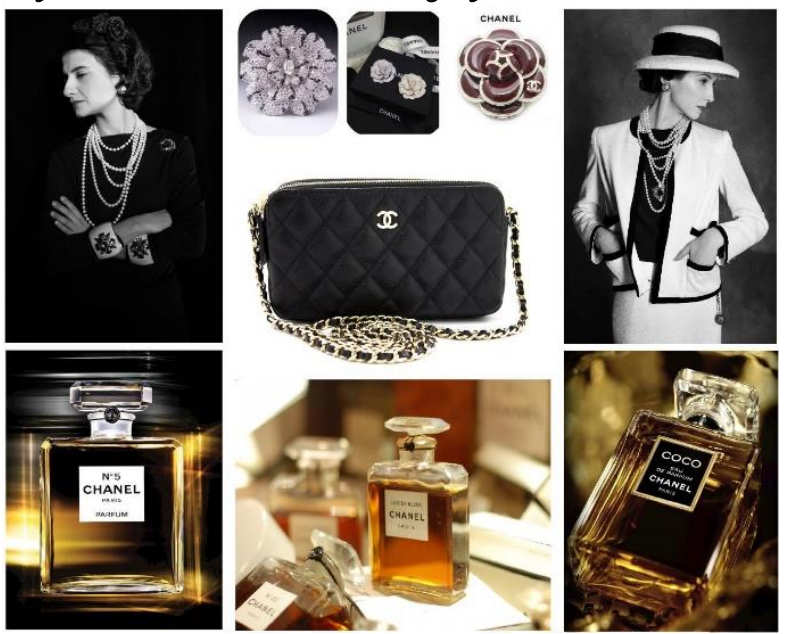

Рисунок 1. Составляющие бренда «Chanel»

Figure 1. Components of the brand «Chanel»

2. «Yves Saint-Laurent». Изюминкой бренда стали бунт, вызов ханжеству и закостенелости. Ив Сен-Лоран был мастером эпатажа. Он подарил миру новый образ женщины свободной от предрассудков, независимой, точно знающей, чего хочет, стильной, властной и уверенной.

Самыми яркими составляющими бренда «YSL» являются:

- брючный костюм-смокинг;

- прозрачная блуза на голое тело;

- пальто-бушлат в духе форменной одежды военных моряков;

- леопардовый принт и сафари (именно в доме Сен-Лоран впервые на подиум выйдет чернокожая модель - Naomi Campbell);

- культовые ароматы «Opium» (из-за своего провокационного названия духи были запрещены к продаже в ряде стран, но, несмотря на критику, «Оріuт» побил все рекорды по продажам и даже спустя десятилетия остается одним из самых популярных ароматов) и «YSL Pour Нотmе» (Ив эпатировал публику тем, что снялся в рекламе этого аромата полностью обнаженным).

3. «Armani». Обязательно надо упомянуть Джорджо Армани с его одноимённым брендом и «звёздным стилем». Главные черты почерка Армани - это совершенный крой, мягкие ткани и минималистический стиль. Джинсы и пиджаки являются визитной карточкой бренда. Рост популярности «Armani» ему обеспечил фильм «Американский жиголо» с Ричардом Гиром. Объясняется это тем, что костюмы, которые носил герой фильма, были созданы модным домом Армани. По сути, Ричард Гир стал лицом бренда, закрепив успех бренда после выхода фильма «Красотка. После этого Джорджо продолжил одевать звёзд в свои наряды, что мы можем частенько увидеть на мероприятиях, освещаемых в СМИ.
Самыми яркими презентациями бренда «Armani» в кинематографе являются следующие картины (рисунок 2): «Неприкасаемые» (костюмы мафиози); «Американский жиголо» (костюмы главного героя - Ричард Гир); «Красотка» (костюмы главного героя - Ричард Гир); «Славные парни» (костюмы гангстеров); «Предмет красоты» (костюмы блестящей пары авантюристов); «Казино рояль» (куртка Джеймса Бонда); «Тринадцать друзей Оушена» (костюмы главного героя Дэнни Оушена (Джордж Клуни) и его приятеля - Расти Райана (Брэд Питт); «Темный рыцарь» (все три фильма Брюс Уэйн (он же Бэтмен) меняет костюмы «Armani» разве что на облачение летучей мыши); «Социальная сеть» (костюмы «Armani» носит Джастин Тимберлейк (Шон Паркер - друг Цукерберга и сооснователь сети «Facebook»); «Ханна. Совершенное оружие» (зеленое пальто и серый костюм Кейт Бланшетт); «Советник» (костюмы главных героев - Майкла Фассбендера и Пенелопы Круз); «Элизиум: Рай не на Земле» (костюмы министрессы обороны планеты Элизиум, которую играет Джоди Фостер); «Волк с Уолл-Стрит» (костюмы успешного биржевого магната Джордана Белфорда, роль которого исполнил Леонардо Ди Каприо); «Унесенные пулями» (костюмы главных героев).
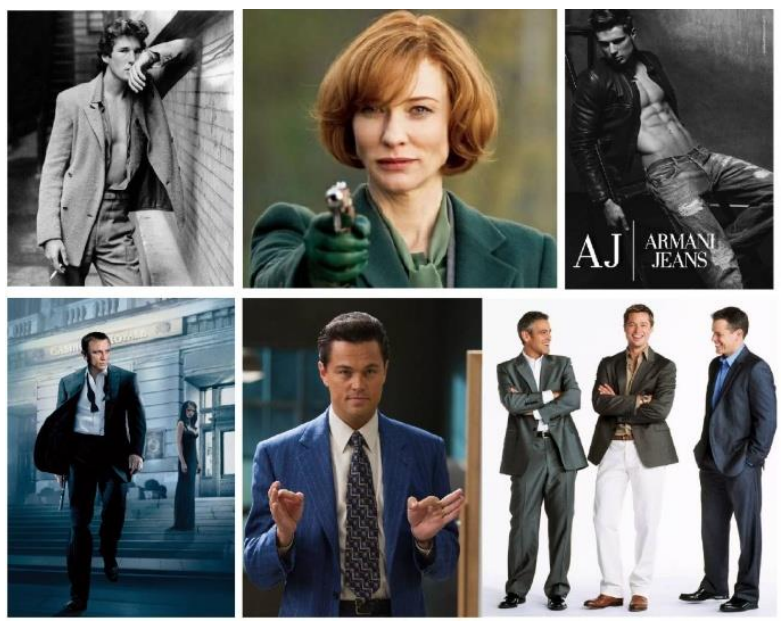

Рисунок 2. «Звёздный стиль» бренда «Armani»

Figure 2. Star Style, «Armani»

4. «Adidas». Крайне действенным способ продвижения также является спонсорство. С 1926 года компания «Adidas» спонсирует футбольные матчи по всему миру.

Адольф Дасслер (основатель компании) изобрёл бутсы со съёмными регулируемыми шипами, в которых в 1954 году играла сборная команда ФРГ. Позже компания «Adidas» занялась производством большого спектра спортивной атрибутики и с 1970 года именно эта компания занялась поставками футбольных мячей для 
чемпионатов по всему миру. После такой долгой истории у любого человека те самые три полоски всегда ассоциируются именно с «Adidas», а про бренд знают в каждом уголке планеты.

5. «Zara». Бренд «Zara»- один из самых известных в Испании, завоевавший мировой рынок. Основной способом продвижения бренда является попадание в трендовую волну (рисунок 3).

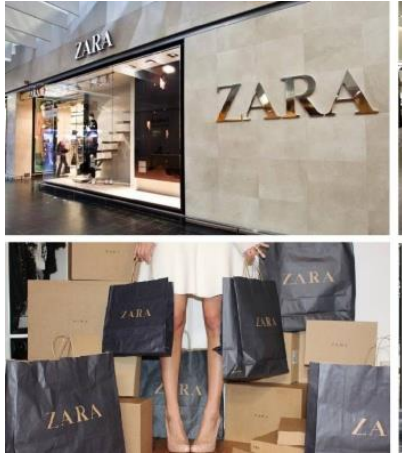

Рисунок 3. Трендовая бренда «Zara»

Figure 3. Trend strategy for promoting the brand Zara

Одежда и аксессуары, которые продаются под этим брендом, стоят весьма недорого, при высоком качестве и оригинальном подходе к созданию продукции. Суть в том, что модельеры «Zara» стараются делать всё «в ногу со временем». Если понаблюдать за показами мод, то можно увидеть там какое-нибудь оригинальное платье, а уже через неделю найти очень похожее в магазинах «Zara».

Рекламная стратегия бренда тесно связана со стратегией продвижения. Их основной целью является воздействие на общественное мнение, которое приводит к максимальным продажам за определенный период, увеличивает количество лояльных потребителей и не уменьшает числа повторяемых, не стимулируемых извне покупок в расчете на одного потребителя.

Существует принципиальное различие между построением системы сбыта и продвижения бренда, принадлежащего нам на правах эксклюзива, и того же бренда, реализуемого и нашими конкурентами.

Гипотетически можно представить следующие варианты: уникальный товар под уникальным брендом (ни товар, ни бренд не продает никто, кроме нас); уникальный товар под неуникальным брендом (новый товар «вписан» в линейку чужого бренда); неуникальный товар под уникальным брендом (такой же товар выпускается и под другими брендами, но наш бренд используем только мы); неуникальный товар под неуникальным брендом (вы- магазин, и продаете то же, что и многие другие магазины).
Однако, вне зависимости от варианта соотношения уникальности товара и уникальности бренда, на рынках брендовых товаров и услуг с каждым годом становится всё более тесно. В связи с чем всем производителям хочется, чтобы именно их товар был наиболее популярным, известным, и, как следствие - продавался лучше, чем у конкурентов. Правильно подобранная рекламная стратегия бренда - это важный шаг, чтобы выйти на рынок или повысить уровень продаж уже известного бренда. Существует множество методов и решений, которые формируют идею рекламной стратегии бренда [15-17].

Рассмотрим 6 основных видов стилистических вариантов брендовых рекламных концепций.

1. Создание настроения или образа.

Данная концепция позволяет создать прочную ассоциацию между брендовой маркой и ощущением определённого настроения, навеянного ключевым образом.

Примером может послужить итальянская компания «Ferrero», успешно использующая именно эту концепцию для продвижения конфет «Raffaello» и «Ferrero Rocher».

Рекламная концепция «Raffaello» направлена на то, чтобы создать романтическое настроение с помощью образа искренней любви (рисунок 4).

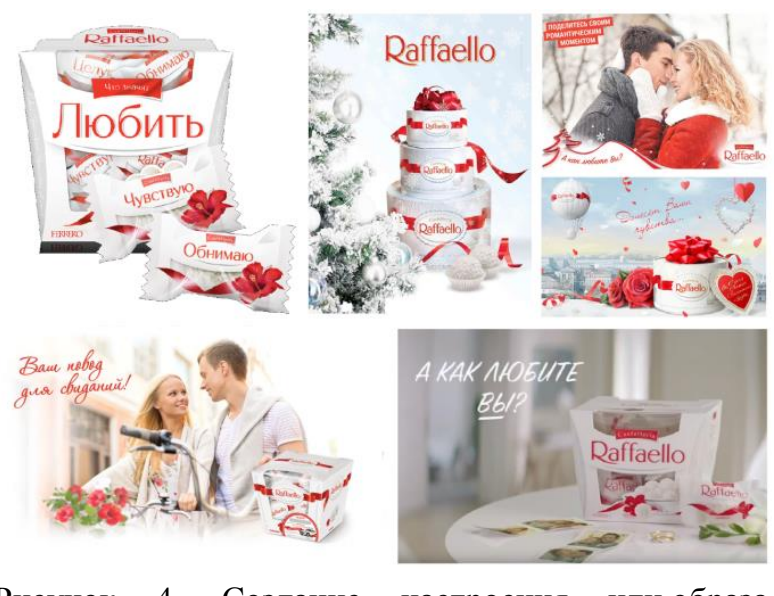

Рисунок 4. Создание настроения или образа «Raffaello»

Figure 4. Creating a mood or image Raffaello

Оформление коробки делает отсылку одновременно и к свадебному торту, и к праздничному подарку (в зависимости от формы коробки) с помощью удачного сочетания красной (символизирует любовь и страсть) [12] и белой (символизирует нежность и чистоту) гаммы в цветовом оформлении [14]. При этом удачно подобранный слоган («Признавайтесь в любви 365 дней в году») позволяет варьировать оформление почти ко всем ключевым праздникам - от 8 марта до Нового Года. 
Рекламная концепция «Ferrero Rocher» направлена на то, чтобы создать праздничное настроение с помощью образа драгоценной роскоши, что достигается за счёт сочетания золотой фольги, выгодно подчёркнутой глубоким коричневым гофре и загадочным нуарным фоном волшебной ночи. Слоганы: «Подарок на все времена!» и «Тем, кто значим!» удачно отражают сущность атмосферы (рисунок 5).
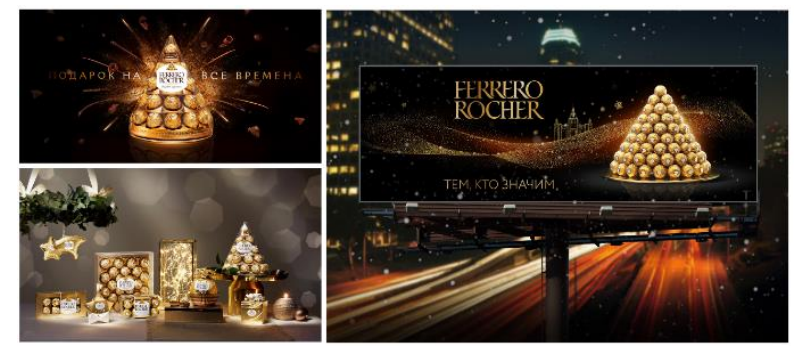

Рисунок 5. Создание настроения или образа «Ferrero Rocher»

Figure 5. Creating a mood or image Ferrero Rocher

\section{2. Акцентирование образа жизни.}

Данная концепция позволяет показать, как брендовая продукция вписывается в тот или иной образ жизни. Примером может послужить рекламная концепция «Baldessarini» (рисунок 6), вписывающая свои парфюмерные линейки в образ жизни брутального, делового мужчины. Удачно подобранный слоган: «Привилегия настоящих мужчин» находит воплощение в акцентировании делового образа жизни через сочетание парфюмерного соблазна с уверенностью в себе и стилем взрослого мужчины.

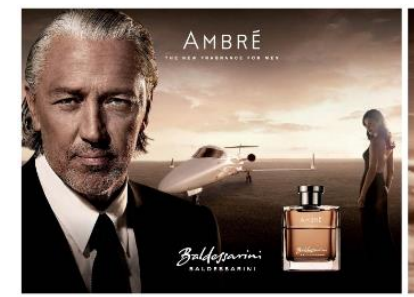

Рисунок 6. Акцентирование образа жизни «Baldessarini»

Figure 6. Emphasizing lifestyle, Baldessarini

Концепция оперирует инструментарием аромомаркетинга, сочетая искушение прованского красного яблока, терпкость амбры и солнечные ноты мандарина, делая отсылку и к мудрому райскому Змию, и к интригующей силе разума, и к увлекательности жизни, как тонкой игры [13].

3. Создание «звёздной легенды».

Данная концепция показывает историю, которую аудитория проживает вместе с культовой личностью, олицетворяющей брендовую продукцию. Это очень популярная рекламная стратегия, которой пользуются многие известные бренды: Николь Кидман и «Chanel № 5», Одри Тоту и «Chanel № 5», Анджелина Джоли и «Guerlain» (рисунок 7).
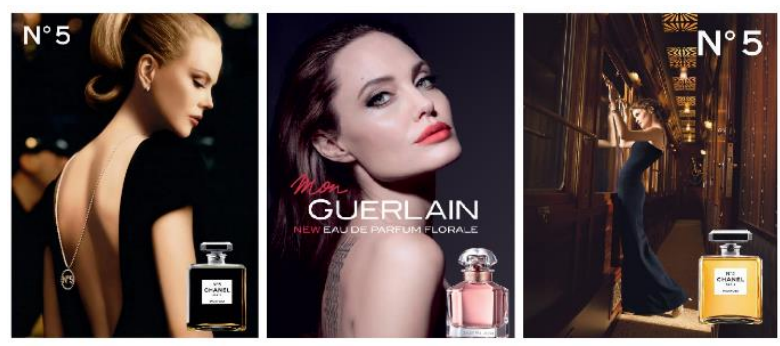

Рисунок 7. Создание «звёздной легенды»

Figure 7. Creation of a star legend

4. Создание фантазийной обстановки.

Данная концепция позволяет создать вокруг брендовой продукции ореол фантазии, волшебного, сказочного сна. Воплощение фантазийной атмосферы «Алисы в Стране Чудес» представил бренд «Chanel» (рисунок 8).
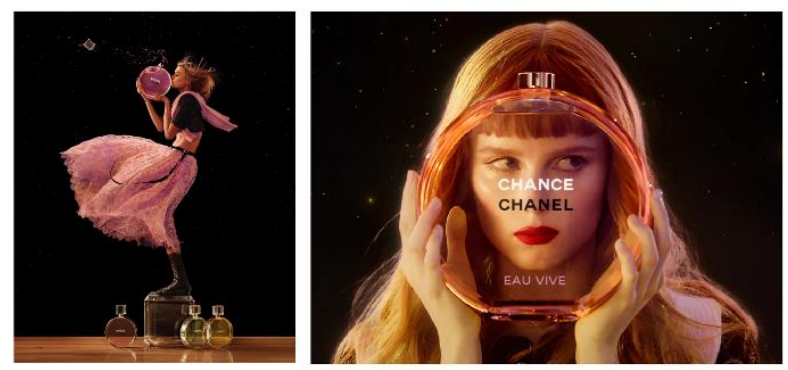

Рисунок 8. Создание фантазийной обстановки «Chanel Chance»

Figure 8. Creating a fantasy environment, Chanel Chance

\section{5. Натурализм.}

Данная концепция крайне популярна в последнее время, отражая экологические тренды общества. Концепция натурализма призвана показать приверженность бренда натуральным, экологически чистым природным компонентам, из которых изготавливается продукция. Эту стратегию блестяще реализовал бренд «Guerlain» в линейке «Aqua allegoria» (рисунок 9).

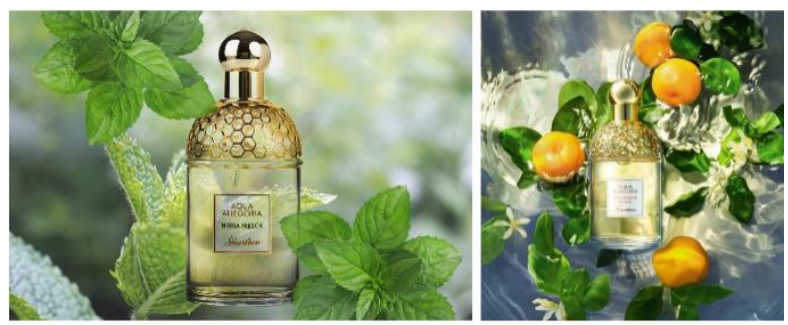

Рисунок 9. Натурализм «Guerlain»

Figure 9. Naturalism, Guerlain 
6. Скандальный эпатаж.

Данная рекламная стратегия является одной из самых противоречивых. Можно привести огромное количество примеров использования эпатажа в рекламных кампаниях.

Их скандальные слоганы повторяют всем миром, а ролики разлетаются в Интернете. Но вопрос: «Насколько эффективна такая стратегия?» по-прежнему остаётся открытым.

Данная стратегия использует четыре основные темы, которые затрагивают глубинные чувства людей и могут гипотетически оскорбить их: эротические чувства, религиозные чувства, этические чувства, понятия морали и нравственности, политкорректность [18].

Одной из первых стратегию скандального эпатажа применила итальянская марка «Benetton». Тонкая работа знаменитого фотографа Оливьеро Тоскани (в 1994 году он был креативным директором компании «Benetton») - «Священник и монашка» совершила настоящую революцию в рекламе. После эта идея получила развитие в рекламной кампании брендового мороженного «Federici».

Ярким примером эпатажа на основе религиозных чувств является пример французской марки «Maritheet Francois Girbaud». В 2003 году компания разместила плакаты, изображавшие женскую версию легендарной фрески Леонардо да Винчи «Тайная вечеря». На рекламном щите были изображены Иисус Христос и все апостолы в полном соответствии с работой великого итальянского мастера, только их роли исполняли девушки, двое из которых обнимали прекрасного полуобнажённого юношу [19].

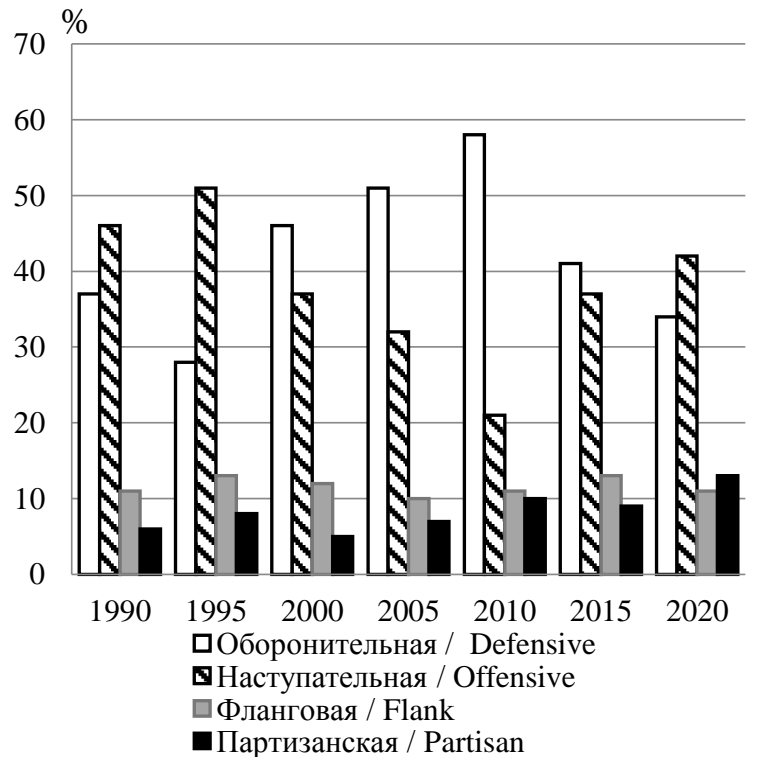

Рисунок 10. Структура предпочтений производителей брендовой продукции при выборе стратегии позиционирования, \% [1]

Figure 10. The structure of preferences of manufacturers of branded products when choosing a positioning strategy, \% [1]
Примером эпатажа на основе этических, нравственных чувств может послужить рекламная компания «Sisley», апеллирующая к зависимости от психоактивных веществ.

Популярность такой рекламной стратегии вполне понятна и оправданна. Скандальный эпатаж затрагивает самые тайные и интимные чувства, именно те чувства, с которыми люди не привыкли делиться, и демонстрировать их публике. С точки зрения психологии, эффективность провокации и эпатажа заключается в том, что, когда атаке подвергаются глубинные, тайные желания, человек подсознательно защищается, отстаивая свои «скелеты в шкафу». И в этот момент он, сам того не желая, максимально активно воспринимает сообщение. Однако скандал требует и чувства меры: он должен оживить действо, но не испортить его, стать «вишенкой на торте».

Таким образом, стратегия рекламного эпатажа - это инструментарий, с которым нужно обращаться очень аккуратно и дозированно.

С целью выявления наиболее результативного стратегического инструментария управления брендом нами были проанализированы данные маркетинговых исследований, проведённых международным рейтинговым агентством «Fitch Ratings Inc.», исследовательской компанией «FDF Group, маркетинговыми агентствами «MegaResearch» и «Infowave» [20].

Структура предпочтений производителей брендовой продукции при выборе стратегии позиционирования (в процентном соотношении) представлена на рисунке 10.

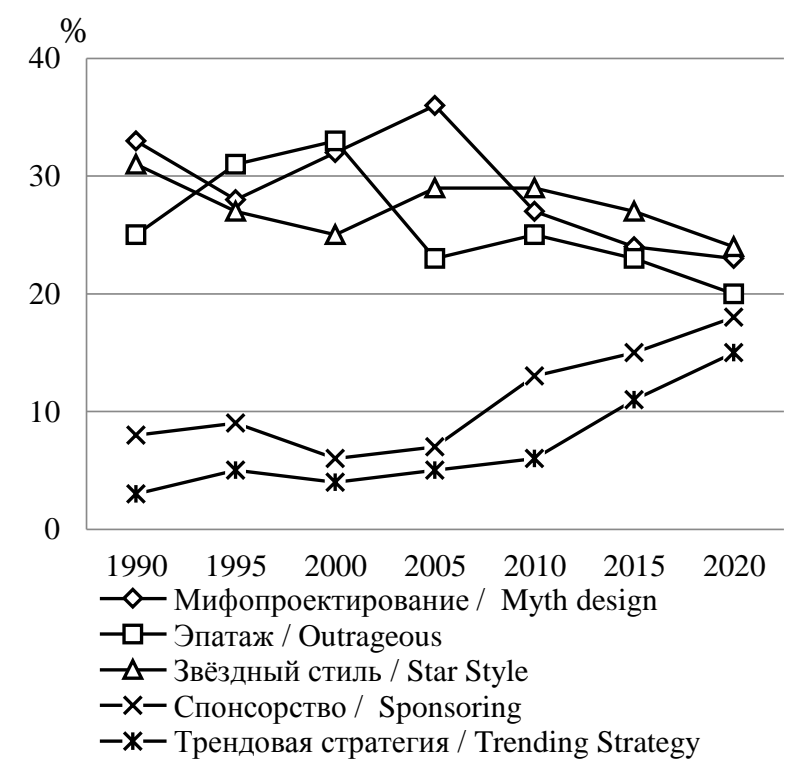

Рисунок 11. Структура предпочтений производителей брендовой продукции при выборе стратегии продвижения, \% [1]

Figure 11. The structure of preferences of manufacturers of branded products when choosing a promotion strategy, \% [1] 
Анализ данных показывает, что производители брендовой продукции отдают предпочтение наступательной и оборонительной стратегии позиционирования, что связано с лидирующими позициями брендовых марок на рынке.

Структура предпочтений производителей брендовой продукции при выборе стратегии продвижения представлена на рисунке 11.

Анализ данных показывает, что производители брендовой продукции отдают предпочтение мифопроектированию, звёздному стилю и эпатажу среди стратегий продвижения. Начиная с периода 2005 года, на рисунке видна динамика в сторону сокращения доли этих стратегий и тенденции к выравниванию с трендовой стратегией и спонсорством.

К 2020 году описанные стратегии гармонизировались в своём долевом соотношении: на первом месте находится стратегия звёздного стиля, $24 \%$ исследованных брендов выбрали именно её, на втором - мифопроектирование (23\%), на третьем - эпатаж $(20 \%)$, на четвёртом - спонсорство (18\%), на пятом - трендовая стратегия (15\%).

Структура предпочтений производителей брендовой продукции при выборе рекламной стратегии представлена на рисунке 12.

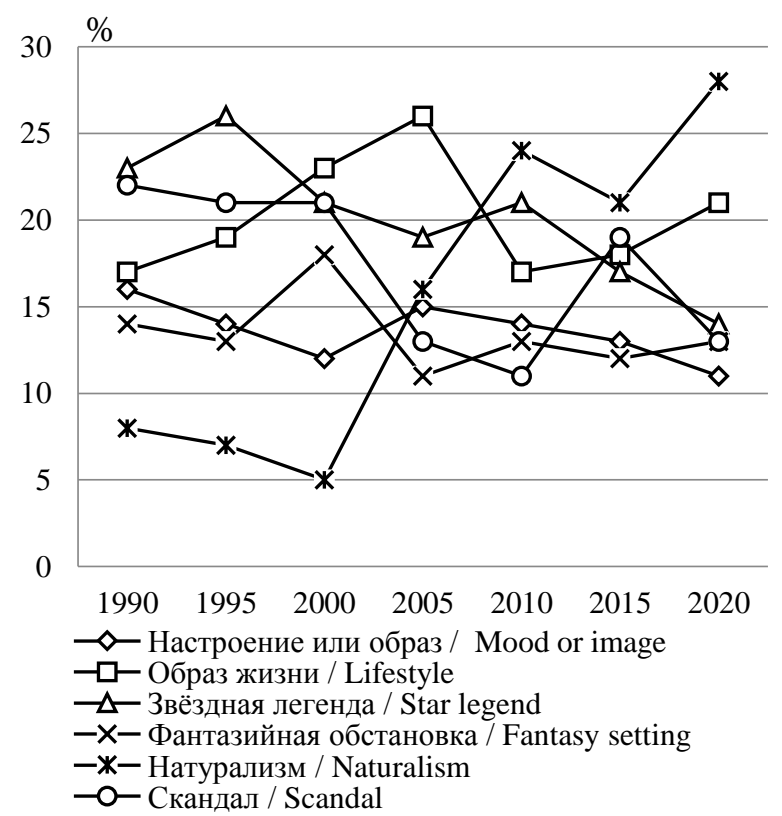

Рисунок 12. Структура предпочтений производителей брендовой продукции при выборе рекламной стратегии, \% [1]

Figure 12. The structure of preferences of manufacturers of branded products when choosing an advertising strategy, \% [1]

Анализ данных показывает, что в разные временные периоды предпочтение отдавалось различным рекламным стратегиям управления брендом.
Период с 1990 г. по 2000 г. предпочтение отдавалось триаде «Звёздная легенда» - «Скандал» - «Образ жизни», при этом за рассматриваемый период лидирующая создание звёздной легенды, встав на одну ступень с технологией скандального эпатажа, уступило пальму первенства акцентированию рекламной стратегии на образе жизни.

В 2005 году, акцентирование на образе жизни поднялось на свой пик в $26 \%$, ознаменовав смену парадигмы. Скандальные технологии в 2005 году сдали свои позиции до $13 \%$, а в 2010 году и вовсе оказались на последнем месте. Таким образом, к 2010 году намеченная смена парадигмы обрела форму новой триады «Натурализм» - «Звёздная легенда» - «Образ жизни».

Акцентирование внимания контактной аудитории на натуральной, экологически чистой и полезной продукции начало завоёвывать рынки сбыта, достигнув доли в $28 \%$ в 2020 году и став трендом XXI века. В период с 2010 года по 2015 год натурализация привносилась в ментальность общества посредством формирования имиджа медийных личностей, ведущих здоровый образ жизни, и их использования в рекламных стратегиях в качестве «лица бренда». В настоящее время «реклама со звездой» по-прежнему актуальна, хотя и находится на третьем месте, уступив паре «Натурализм» - «Образ жизни» (28\% и $21 \%$ соответственно).

\section{Заключение}

Проведённое нами исследование позволило провести сравнительный анализ стратегий управления брендом.

По результатам анализа были сделаны следующие выводы:

- производители брендовой продукции отдают предпочтение наступательной и оборонительной стратегии позиционирования, что связано с лидирующими позициями брендовых марок на рынке;

- производители брендовой продукции отдают предпочтение мифопроектированию, звёздному стилю и эпатажу среди стратегий продвижения (начиная с периода 2005 года, наблюдается динамика в сторону сокращения доли этих стратегий и тенденции к выравниванию с трендовой стратегией и спонсорством, к 2020 году описанные стратегии гармонизировались в своём долевом соотношении);

- в разные временные периоды предпочтение отдавалось различным рекламным стратегиям управления брендом: период с 1990 г. по 2000 г. предпочтение отдавалось триаде «Звёздная легенда» - «Скандал» - «Образ жизни», в 2005 году, акцентирование на образе жизни поднялось на свой пик в $26 \%$, ознаменовав 
смену парадигмы, и уже к 2010 году парадигма обрела форму новой триады «Натурализм» «Звёздная легенда» - «Образ жизни», который с 2020 года сформировался в пару «Натурализм»-«Образ жизни».

Подводя итог, можно сделать вывод о том, что в процессе формирования системы управления брендом используются три, взаимосвязанных в единый комплекс, стратегии: стратегия позиционирования, стратегия продвижения и рекламная стратегия бренда.

При реализации комплекса мероприятий по управлению брендом выбор той или иной стратегии и их комбинаций будет обусловлен текущей ситуацией на рынках брендовой продукции, парадигмальными трендами развития общества и потребительскими ожиданиями целевой аудитории.

\section{Литература}

1 Mueller D.S., Stewart A., Clifford R., Iles L. et al. Using Design Interventions to Develop Communication Solutions for Integrated Pest Management // Journal of Integrated Pest Management. 2020. V. 11. №. 1. P. 10. Doi: 10.1093/jipm/pmaa010

2 Ghobehei M., Sadeghvaziri F., Ebrahimi E., Bakeshloo K.A. The effects of perceived brand orientation and perceived service quality in the higher education sector // Eurasian Business Review. 2019. V. 9. №. 3. P. 347-365. doi: 10.1007/s40821018-00115-4

3 Теняева О.В. Половые различия проявления эмоционального интеллекта в профессиональной деятельности современных руководителей // Прикладная юридическая психология. 2020. № 2 (51). С. 101-106.

4 Теняева О.В., Шурикова Т.И. Подходы к пониманию феномена эмоционального интеллекта в зарубежной и отечественной психологии // Педагогика и психология как ресурс развития современного общества: Материалы $\mathrm{X}$ Международной научно-практической конференции. Рязань: «Концепция». С. 311-314.

5 Фомина Н.А. Целостный анализ проявлений в речи лингвистических и психологических характеристик языковой личности // Психолого-педагогический поиск. 2007. № 6. С. 100-106.

6 Tenyaeva O.V., Bespalova T.M. Patriotism and civic identity as basis of professional competence of military students // The European Proceedings of Social \& Behavioural Sciences. Edited by: Prof. Valeria Chernyavskaya and Prof. Holger Kuße. 2018. P. 392-397.

7 Ciunova-Shuleska A., Osakwe C.N., Palamidovska-Sterjadovska N. Complementary impact of capabilities and brand orientation on SMBs performance // Journal of Business Economics and Management. 2016. V. 17. №. 6. P. 1270-1285. doi: $10.3846 / 16111699.2016 .1181101$

8 Moreira A.C., Fortes N., Santiago R. Influence of sensory stimuli on brand experience, brand equity and purchase intention // Journal of Business Economics and Management. 2017. V. 18. №. 1. P. 68-83. doi: 10.3846/16111699.2016.1252793

9 Onișor L.F., Ioniță D. How advertising avoidance affects visual attention and memory of advertisements // Journal of Business Economics and Management. 2021. V. 22. №. 3. P. 656-674. doi: 10.3846/jbem.2021.14546

10 Klepek M., Starzyczná H. Marketing communication model for social networks // Journal of Business Economics and Management. 2018. V. 19. №. 3. P. 500-520. doi: 10.3846/jbem.2018.6582

11 Лисс А.А., Линкевич Н.А., Семенков А.И., Клипов Д.Д. и др. Программно-аппаратный комплекс для централизованного управления состоянием видеопроекторов в учебных аудиториях // Вестник НГУЭУ. 2017. № 1. С. $297-315$.

12 Коган А.Б., Новиков А.В. Генезис теории оценки эффективности реальных инвестиций // Вестник НГУЭУ. 2017. № 2. C. 10-18.

13 Глущенко К.П. Проблемы оценки крупномасштабных проектов // Вестник НГУЭУ. 2019. № 4. С. 26-40.

14 Bespalova T.M., Tenyaeva O.V., Kudinov S.I. Self-assessment of personal civic identity in adolescents // The European Proceedings of Social \& Behavioural Sciences EpSBS. 2019. P. 1-8.

15 Vera J., Espinosa M. Consumer involvement as a covariant effect in rethinking the affective-cognitive relationship in advertising effectiveness // Journal of Business Economics and Management. 2019. V. 20. №. 2. P. 208-224. doi: 10.3846/jbem.2019.8099

16 Lin F., Siu W.S. Exploring brand management strategies in Chinese manufacturing industry // Journal of Brand Management. 2020. V. 27. №. 1. P. 48-76. doi: 10.1057/s41262-019-00166-6

17 Likoum S.W.B. et al. Market-sensing capability, innovativeness, brand management systems, market dynamism, competitive intensity, and performance: an integrative review // Journal of the Knowledge Economy. 2020. V. 11. №. 2. P. $593-613$. doi: 10.1007/s13132-018-0561-x

18 Heding T., Knudtzen C. F., Bjerre M. Brand Management: Mastering Research, Theory and Practice. Routledge, 2020.

19 Iyer P., Davari A., Zolfagharian M., Paswan A. Market orientation, positioning strategy and brand performance // Industrial Marketing Management. 2019. V. 81. P. 16-29. doi: 10.1016/j.indmarman.2018.11.004

20 Jestratijevic I., Rudd N. A., Uanhoro J. Transparency of sustainability disclosures among luxury and mass-market fashion brands // Journal of Global Fashion Marketing. 2020. V. 11. №. 2. P. 99-116. doi: 10.1080/20932685.2019.1708774

\section{References}

1 Mueller D.S., Stewart A., Clifford R., Iles L. et al. Using Design Interventions to Develop Communication Solutions for Integrated Pest Management. Journal of Integrated Pest Management. 2020. vol. 11. no. 1. pp. 10. doi: 10.1093/jipm/pmaa010

2 Ghobehei M., Sadeghvaziri F., Ebrahimi E., Bakeshloo K.A. The effects of perceived brand orientation and perceived service quality in the higher education sector. Eurasian Business Review. 2019. vol. 9. no. 3. pp. 347-365. doi: 10.1007/s40821018-00115-4 
3 Tenyaeva O.V. Sex differences in the manifestation of emotional intelligence in the professional activities of modern leaders. Applied legal psychology. 2020. no. 2 (51). pp. 101-106. (in Russian).

4 Tenyaeva O.V., Shurikova T.I. Approaches to understanding the phenomenon of emotional intelligence in foreign and domestic psychology. Pedagogy and psychology as a resource for the development of modern society: Materials of the X International Scientific and Practical Conference. Ryazan, "Concept". pp. 311-314. (in Russian).

5 Fomina N.A. A holistic analysis of the manifestations in speech of the linguistic and psychological characteristics of the linguistic personality. Psychological and pedagogical search. 2007. no. 6. pp. 100-106. (in Russian).

6 Tenyaeva O.V., Bespalova T.M. Patriotism and civic identity as basis of professional competence of military students. The European Proceedings of Social \& Behavioural Sciences. 2018. pp. 392-397.

7 Ciunova-Shuleska A., Osakwe C.N., Palamidovska-Sterjadovska N. Complementary impact of capabilities and brand orientation on SMBs performance. Journal of Business Economics and Management. 2016. vol. 17. no. 6. pp. $1270-1285$. doi: 10.3846/16111699.2016.1181101

8 Moreira A.C., Fortes N., Santiago R. Influence of sensory stimuli on brand experience, brand equity and purchase intention. Journal of Business Economics and Management. 2017. vol. 18. no. 1. pp. 68-83. doi: 10.3846/16111699.2016.1252793

9 Onișor L.F., Ioniță D. How advertising avoidance affects visual attention and memory of advertisements. Journal of Business Economics and Management. 2021. vol. 22. no. 3. pp. 656-674. doi: 10.3846/jbem.2021.14546

10 Klepek M., Starzyczná H. Marketing communication model for social networks. Journal of Business Economics and Management. 2018. vol. 19. no. 3. pp. 500-520. doi: 10.3846/jbem.2018.6582

11 Liss A.A., Linkevich N.A., Semenkov A.I., Klipov D.D. et al. Hardware and software complex for centralized control of the state of video projectors in classrooms. Vestnik NSUEM. 2017. no. 1. pp. 297-315. (in Russian).

12 Kogan A.B., Novikov A.V. Genesis of the theory of evaluating the effectiveness of real investments. Vestnik NSUEM. 2017. no. 2. pp. 10-18. (in Russian).

13 Glushchenko K.P. Problems of evaluating large-scale projects. Vestnik NSUEM. 2019. no. 4. pp. 26-40. (in Russian).

14 Bespalova T.M., Tenyaeva O.V., Kudinov S.I. Self-assessment of personal civic identity in adolescents. The European Proceedings of Social \& Behavioural Sciences EpSBS. 2019. pp. 1-8.

15 Vera J., Espinosa M. Consumer involvement as a covariant effect in rethinking the affective-cognitive relationship in advertising effectiveness. Journal of Business Economics and Management. 2019. vol. 20. no. 2. pp. 208-224. doi: 10.3846/jbem.2019.8099

16 Lin F., Siu W.S. Exploring brand management strategies in Chinese manufacturing industry. Journal of Brand Management. 2020. vol. 27. no. 1. pp. 48-76. doi: 10.1057/s41262-019-00166-6

17 Likoum S.W.B. et al. Market-sensing capability, innovativeness, brand management systems, market dynamism, competitive intensity, and performance: an integrative review. Journal of the Knowledge Economy. 2020. vol. 11. no. 2. pp. $593-613$. doi: $10.1007 / \mathrm{s} 13132-018-0561-\mathrm{x}$

18 Heding T., Knudtzen C. F., Bjerre M. Brand Management: Mastering Research, Theory and Practice. Routledge, 2020.

19 Iyer P., Davari A., Zolfagharian M., Paswan A. Market orientation, positioning strategy and brand performance. Industrial Marketing Management. 2019. vol. 81. pp. 16-29. doi: 10.1016/j.indmarman.2018.11.004

20 Jestratijevic I., Rudd N. A., Uanhoro J. Transparency of sustainability disclosures among luxury and mass-market fashion brands. Journal of Global Fashion Marketing. 2020. vol. 11. no. 2. pp. 99-116. doi: 10.1080/20932685.2019.1708774

\section{Сведения об авторах}

Юлия О. Лящук, доцент, кафедра бизнеса и управления, Московский университет имени С.Ю. Витте (филиал в г. Рязань), Первомайский проспект, 62, г. Рязань, Россия, ularzn@mail.ru

Dhttps://orcid.org/0000-0002-3612-1707

Ольга В. Платонова к.с-х.н., старший лейтенант внутренней службы, кафедра экономической теории, географии и экологии, Академия права и управления Федеральной службы исполнения наказания, ул. Сенная, д.1, г. Рязань, Россия,, platva-82@mail.ru

(Dhttps://orcid.org/0000-0002-3259-1031

\section{Вклад авторов}

Авторы в равной степени принимали участие в написании рукописи и несут ответственность за плагиат

Конфликт интересов

Авторы заявляют об отсутствии конфликта интересов.

\section{Information about authors}

Yuliya O. Lyashchuk associate professor, business and management department, Moscow University named after S.Y. Witte (Ryazan branch), Pervomaisky avenue, 62, Ryazan, Russia, ularzn@mail.ru (Dhttps://orcid.org/0000-0002-3612-1707

Olga V. Platonova Cand. Sci. (Agric.), senior lieutenant of the internal service, Department of Economic Theory, Geography and Ecology, Academy of Law and Management of the Federal Service for the Execution of Punishment, str. Sennaya, 1, Ryazan, Russia, platva-82@mail.ru

(Dhttps://orcid.org/0000-0002-3259-1031

Contribution

Authors are equally involved in the writing of the manuscript and are responsible for plagiarism

\section{Conflict of interest}

The authors declare no conflict of interest.

\begin{tabular}{ccc}
\hline Поступила 28/12/2020 & После редакции 08/02/2021 & Принята в печать 03/03/2021 \\
\hline & & Accepted 03/03/2021 \\
\hline Received 28/12/2020 & Accepted in revised 08/02/2021 & . \\
\hline
\end{tabular}

